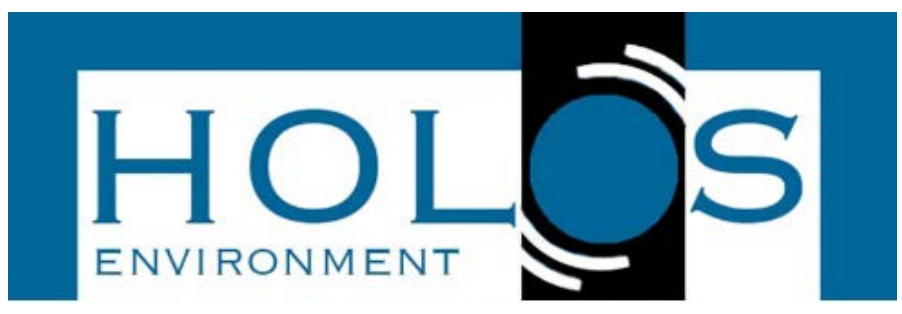

\title{
EFEITOS DA APLICAÇÃO DE VINHAÇA "IN NATURA" OU CONCENTRADA ASSOCIADO AO N-FERTILIZANTE EM SOQUEIRA DE CANA-DE-AÇÚCAR E NO AMBIENTE
}

\section{EFFECTS OF VINASSE APPLICATION "IN NATURA" OR CONCENTRATED ASSOCIATED WITH N-FERTILIZER OF RATOON SUGARCANE AND ENVIRONMENT}

\author{
Gael Silvia Peñaranda Liendo da Silva ${ }^{1}$; Fábio Cesar da Silva ${ }^{2,3}$; Bruno Jose Rodri- \\ gues Alves"; Edson Tomaz"1; Ronaldo Severiano Berton ${ }^{5}$; Luis Fernando Sanglade \\ Marchiori ${ }^{3,6}$; Felipe Gomes da Silveira ${ }^{3}$
}

Artigo recebido em: 08/08/2017 e aceito para publicação em: 01/02/2019.

DOI: http://dx.doi.org/10.14295/holos.v19i1.12212

Resumo: O objetivo deste trabalho foi avaliar o efeito da fertilização com vinhaça "in natura" ou concentrada com e sem adição de fertilizante nitrogenado na produtividade, qualidade da cana-de-açúcar e dinâmica do $\mathrm{N}$ e seus reflexos na fertilidade, verificar ainda, se há influência dos tratamentos aplicados na biometria da planta, bem como, avaliar se a demanda nutricional da cultura foi atendida, através de análise de sua composição foliar aos quatro meses. O experimento foi realizado em campo com cana soca no $2^{\circ}$ corte, com delineamento experimental em blocos ao acaso, com total 30 parcelas, sendo cinco tratamentos com seis repetições. Os tratamentos foram: T1 - Vinhaça "in natura" (120 m³.ha-1), T2 - Vinhaça (120 m³.ha-1) + $60 \mathrm{Kg}$ de N-ureia.ha-1, T3 - Vinhaça concentrada (20 $\mathrm{m}^{3}$.ha-1), T4 - $60 \mathrm{Kg}$ de N-ureia.ha-1 e T5- Testemunha. Constatou-se que não houve diferença significativa para a qualidade tecnológica da cana de açúcar, entretanto para a qualidade do caldo e produtividade os tratamentos T1, T2 e T3 apresentaram concentração de K (potássio) superior aos tratamentos T4 e T5. Entre os tratamentos de fertilidade foliar constataram-se valores que atendem a suficiência da cultura. Para a fertilidade do solo temos diferenças significativas de K, entre profundidades, localização e tratamentos. Houve efeito da aplicação da vinhaça e fertilizante nitrogenado significativamente relacionamento com parâmetros do solo (NO3, C solúvel e umidade).

Palavras-chave: Vinhaça concentrada. Efluente agroindustrial. Balanço de nitrogênio.

Abstract: The objective was to evaluate the fertilization with vinasse "in natura" or concentrated and nitrogen fertilizer on yield, quality of sugarcane and dynamics of $\mathrm{N}$, reflecting the improvement of soil fertility by adding nutrients, checking the influence of the treatments applied to the biometrics of the

${ }^{1}$ Faculdade de Engenharia Química, Universidade Estadual de Campinas - UNICAMP. Campinas. Emails: gaelsilvia@gmail.com, etomaz@feq.unicamp.br

2 Embrapa Informática Agropecuária. Campinas. E-mail: fabio.silva@embrapa.br.

${ }^{3}$ Faculdade de Tecnologia "Deputado Roque Trevisan"(FATEC). Piracicaba,SP. E-mails:

fabio.silva@embrapa.br, sanglade.If@hotmail.com, secretaria@fatecpiracicaba.edu.br

4 Pesquisador da Embrapa Agrobilogia, Seropedica, RJ. E-mail: bruno.alves@embrapa.br

${ }^{5}$ Pesquisador do Instituto Agronômico de Campinas -IAC/APTA. Campinas, SP. E-mail: berton@iac.sp.gov.br

${ }^{6}$ Diretor da Fazenda Areão da Universidade de São Paulo - ESALQ/USP, Piracicaba, SP. E-mail: sanglade.If@usp.br

Holos Environment (2019), 19 (1): 1-21. 1 
plant and also assess if the nutritional adequacy of culture has been achieved through the manifestation of its leaf up in the four months. The experiment was carried out in the field with rattoon cane in the 2 nd cut, using an experimental randomized block design, with a total of 30 plots, where we have 5 treatments with 6 repetitions, the treatments were carried out according to the following proportions: T1 vinasse "in natura" (120 m3 / ha), T2 vinasse (120 m3 / ha) + $60 \mathrm{~kg}$ of urea- $\mathrm{N}$, T3 concentrated vinasse (20 m3 / ha), T4- $60 \mathrm{~kg}$ of urea-N / ha T5- Witness. It was found that there was no significant difference for the technological quality of sugarcane, however the quality of the broth and productivity there, since the treatments T1, T2 and T3 showed concentrations of $\mathrm{K}$ (potassium) higher than the treatments T4 and T5. Among the foliar fertility treatments was found values that meet the sufficiency of culture. For the soil fertility $\mathrm{K}$ we have significant differences among depths, localization and treatment. Looking in-depth the effects of the application of the vinasse and the nitrogen fertilizer, there is a significant co-relationin soil parameters (NO3, soluble $\mathrm{C}$ and humidity).

Palavras-chave: Concentration of vinasse. Agroindustrial effluent. Nitrogen balance.

\section{INTRODUÇÃO}

O Brasil é um dos maiores produtores mundiais de cana-de-açúcar, com uma produção estimada de 684 milhões de toneladas na safra 2016/2017 (BRASIL, 2017). A contribuição da cana-de-açúcar na matriz energética do país foi de aproximadamente $16,4 \%$ em 2011, com estimativas de crescimento até 2021 , podendo chegar a representar 21,2\% (Canavieiros, 2012). As grandes demandas por novas fontes de energia limpa e sustentável contribuíram para o investimento em etanol de cana no país (TEODORO, 2011), o que traz consigo todo um conjunto de efluentes e resíduos sólidos.

A vinhaça, principal efluente resultante da destilação do mosto fermentado, devido a sua grande produção, que pode chegar a proporção de 18 litros de efluente por litro de etanol produzido, vem sendo estudada por pesquisadores da ESALQ (Escola Superior de Agricultura Luiz de Queiroz) desde 1950 (Almeida, 1952; Gloria e colaboradores, 1973 e 1976; Rodella e Ferrari, em 1977, entre outros). Tais estudos tiveram como objetivos, avançar o conhecimento da natureza e composição da vinhaça, visando seu uso na agricultura e suas interações com as propriedades do solo. Segundo Copersucar (1978) ocorre elevação da acidez do solo, entretanto Mattiazzo e Gloria $(1985,1987)$, observaram que, apesar da vinhaça ser ácida, ocorria o contrário, ela elevava o $\mathrm{pH}$ do solo a ser aplicada, inclusive melhorando suas propriedades físicas, em seu trabalho mostraram que após 183 dias da aplicação de vinhaça a um Regossol, seu pH, passou de 5,0 para 7,5 e um Latossol de 5,2 passou para 6,6 . 
As pesquisas realizadas nos últimos 30 anos, demonstram a viabilidade de se utilizar a vinhaça como adubo, especialmente pelo conteúdo de potássio, segundo diversos autores (PENATTI et al., 1988, 2001; PEIXOTO, 1986 e 2006; ORLANDO FILHO et al., 1995; BARBOSA, 2006), além de fornecer outros macros e micros nutrientes necessários para o bom desenvolvimento da planta (MORO, 2011), transformando um efluente com grande capacidade poluidora em produto fertilizante de excelente qualidade. Tal prática de aplicação de vinhaça na lavoura possui legislação própria, isto é, a quantidade aplicada de vinhaça está regulamentada pela norma paulista para vinhaça "Norma Técnica CETESB - Portaria P. 4231". Essa norma paulista, se baseia na saturação de potássio $(K)$ na capacidade de troca de cátions (CTC) do solo para calcular à dose de vinhaça a ser aplicada para cada taIhão em função do limite de saturação de potássio no cálculo da capacidade de troca catiônica (CTC).

O principal problema da utilização da vinhaça como biofertilizante se localiza nos custos de transporte até os locais de aplicação, assim, para levar a vinhaça para areas mais distante, as usinas têm optado pela sua concentração através da redução do conteúdo de água e consequentemente aumento do teor de potássio (K). Albers (2007), num estudo comparando as vinhaças concentrada e "in natura" destacou: i) reaproveitamento do vapor condensado como água para em embebição do bagaço nas moendas e outros fins; ii) neutralização da contaminação do lençol freático; e iii) viabilização do transporte a distâncias maiores, reduzindo o custo de deslocamento da vinhaça.

Há poucos resultados de utilização agrícolas de vinhaça concentrada na cana-de-açúcar, na pesquisa de Barbosa et al. (2006), utilizando vinhaça concentrada em doses equivalente de 0, 180 e 270 kg.ha-1 de K combinado em diversas doses e formulas de adubos minerais aplicados em solo Argissolo vermelho amarelo, concluíram que houve aumento de produtividade por área colhida sem alterar significativamente as variáveis tecnológicas do caldo.

De acordo com Albers (2007), considerando-se a vinhaça concentrada a 35\%, para se atingir $185 \mathrm{Kg} \mathrm{K}_{2} \mathrm{O}$ ha $^{-1}$, resultaria em uma dosagem recomendada em torno de $5,3 \mathrm{~m}^{3}$.ha-1, que poderia ser feita com aplicadores.

O principal N-fertilizante sólido disponível no mundo é a ureia. No Brasil representa 50\% dos adubos nitrogenados, em parte por conta de seu baixo custo por unidade de $\mathrm{N}$ e maior facilidade de produção (PENATTI, 2013). 
O presente trabalho teve como objetivo verificar a influência da fertilização nitrogenada e da utilização de vinhaça ("in natura" e concentrada) na cultura da canade-açúcar, em aplicação em soqueira, na produtividade de colmos, na qualidade da matéria prima e na dinâmica de nitrogênio no ambiente. Além disso, verificar mudanças de qualidade do caldo, em especial pela elevação dos teores de N.

\section{MATERIAL E MÉTODOS}

O ensaio foi conduzido na Fazenda Areão, pertencente à ESALQ (USP), no município de Piracicaba (SP), no período de Dezembro de 2012 à Novembro de 2013. Em Piracicaba, o clima é quente e temperado, a pluviosidade é relativamente bem distribuída ao longo do ano e mesmo no mês mais seco podem ocorrer algumas chuvas. O clima é classificado como Cfa segundo a Köppen e Geiger, a temperatura média é $20.8^{\circ} \mathrm{C}$ e a pluviosidade média anual de $1255 \mathrm{~mm}$.

O solo onde se realizou o ensaio foi classificado pela EMBRAPA SOLOS (Manejo e Conservação do Solo e da Água), como ARGISSOLO VERMELHOAMARELO eutrófico típico. Trata-se de solos constituídos por material mineral como argilas de baixa atividade e horizonte B textural, moderadamente bem drenados, profundos, cores desde vermelha até amarela no horizonte diagnóstico de subsuperfície. Por via da regra apresentam, um gradiente textural elevado e presença de serosidade. Esses solos apresentam sérias limitações devidas à maior susceptibilidade à erosão no caso dos solos com caráter abrupto, que se agrava a medida aumenta a declividade do terreno. (EMBRAPA, 2013)

O experimento foi conduzido em cana soca de $2^{\circ}$ corte, e a variedade utilizada foi a SP82-3250. A área foi dividida em 6 blocos (repetições), cada um com cinco parcelas (tratamentos aplicados). A aplicação dos tratamentos foi realizada no dia 5 de dezembro de 2012, distribuindo-se a vinhaça de forma homogênea, conforme os volumes recomendados nos tratamentos, utilizando-se uma mangueira com vazão conhecida e utensílios de apoio para controlar a aplicação.

A vinhaça concentrada foi originária da unidade Usina Costa Pinto de Piracicaba, pertencente ao Grupo Cosan/Raizen, que utiliza evaporadores de fluxo descendente do tipo névoa turbulento, tecnologia conhecida como T.A.S.T.E. (Thermally Accelerated Short Time Evaporation). Tal vinhaça foi produzida com 22\% de teor de sólidos, com volume reduzido em aproximadamente cinco vezes. Amostras de vi- 
nhaça foram retiradas antes da aplicação para caracterização de nitrogênio total, nitrogênio amoniacal, carbono orgânico e potássio entre outros. Essas análises foram realizadas segundo os protocolos e normas da CETESB, pelo Instituto Brasileiro de Análise IBRA (Tabela 1).

O delineamento experimental utilizado foi blocos ao acaso, tendo 6 repetições e 5 tratamentos. As parcelas foram constituídas por cinco linhas de 10 metros, espaçadas de 1,40 m, sendo área útil de 33,6 $\mathrm{m}^{2}$.

Os 5 tratamentos utilizados foram: T1- Vinhaça in natura $\left(120 \mathrm{~m}^{3} / \mathrm{ha}\right)$, T2Vinhaça in natura $\left(120 \mathrm{~m}^{3} / \mathrm{ha}\right)+$ Ureia $(60 \mathrm{Kg} / \mathrm{ha})$, T3- Vinhaça concentrada (20 $\left.\mathrm{m}^{3} / \mathrm{ha}\right)$, T4- Ureia (200 kg/ha) e T5- Testemunha.

A fertilidade do solo foi monitorada na camada arável $(0-20 \mathrm{~cm})$ a cada semana para dinâmica de N (N-Amônia, N-Nitrato), foram analisadas 300 amostras de solo, para a determinação de nitrogênio em suas formas de $\mathrm{NH}_{4}$ e $\mathrm{NO}_{3} / \mathrm{NO}_{2}$, o procedimento está descrito em SILVA (2009). Para a determinação de nitrogênio inorgânico pelo método da destilação a vapor, usaram-se o método IME-RES-034 do laboratório de Análise Química de Fertilizantes e Resíduos do Instituto Agronômico Campinas IAC.

No pico de máximo crescimento da planta, foi determinado o carbono solúvel e realizada a caracterização do perfil do solo. Foram analisadas 300 amostras no Laboratório de Ciclagem de Nutrientes da Embrapa Agrobiologia, e a determinação de Carbono solúvel das amostras de solo foi realizada pela metodologia para a determinação do carbono da biomassa microbiana do solo (BMSC), segundo o comunicado técnico no 98 da Embrapa.

Para coletas, preparo de amostras e análises tecnológicas no caldo e teores de $\mathrm{N}$ e $\mathrm{K}$, seguiu-se a metodologia CONSECANA (2006). Essas coletas foram realizadas em três épocas a saber, no início ( $2^{\mathrm{a}}$ quinzena de abril), meio ( $1^{\mathrm{a}}$ quinzena de julho) e final (final de outubro) da safra. Para as análises nutricionais da planta, utilizou-se metodologia descrita em SILVA (2009). Os dados foram submetidos à análise de variância (ANOVA) conforme o delineamento descrito no item material e métodos. As médias foram comparadas pelo teste de Tukey $(P<0,05)$. 
Tabela 1 - Caracterização da vinhaça "in natura" e concentrada utilizadas no experimento

\begin{tabular}{|c|c|c|c|c|c|c|}
\hline \multirow{2}{*}{$\begin{array}{c}\text { Descrição } \\
\mathrm{pH}\end{array}$} & \multicolumn{2}{|c|}{$\begin{array}{l}\text { Vinhaça } \\
\text { in natura }\end{array}$} & \multirow{2}{*}{$\begin{array}{l}\text { Média(1) } \\
3,98\end{array}$} & \multicolumn{2}{|c|}{$\begin{array}{c}\text { Vinhaça } \\
\text { concentrada }\end{array}$} & \multirow{2}{*}{$\begin{array}{c}\text { Média(2) } \\
3,98\end{array}$} \\
\hline & 3,93 & 4,02 & & 3,99 & 3,97 & \\
\hline $\begin{array}{c}\text { Resíduo não filtrável } \\
\text { (Sólidos suspensos) } \\
\text { (mg/L) }\end{array}$ & 34200,00 & 14800,00 & 24500,00 & 29100,00 & 41200,00 & 35150,00 \\
\hline $\begin{array}{c}\text { Dureza Total } \mathrm{CaCO}_{3} \\
(\mathrm{mg} / \mathrm{L})\end{array}$ & 2714,98 & 4606,35 & 3660,67 & 8730,90 & 8356,36 & 8543,63 \\
\hline $\begin{array}{l}\text { Carbono Orgânico } \\
\text { (titulação)( \%) }\end{array}$ & 2,07 & 5,26 & 3,67 & 7,99 & 6,59 & 7,29 \\
\hline $\begin{array}{c}\text { Conductividade } \\
{[\mathrm{mS} / \mathrm{cm}]}\end{array}$ & 9,34 & 11,11 & 10,23 & 17,81 & 20,95 & 19,38 \\
\hline $\begin{array}{l}\text { Nitrato } \mathrm{NO}_{3}-\mathrm{N} \\
(\mathrm{mg} / \mathrm{L})\end{array}$ & 134,00 & 125,00 & 129,50 & 415,00 & 330,00 & 372,50 \\
\hline $\begin{array}{l}\text { Nitrito } \mathrm{NO}_{2}-\mathrm{N} \\
(\mathrm{mg} / \mathrm{L})\end{array}$ & 3,40 & 11,00 & 7,20 & 18,00 & 16,50 & 17,25 \\
\hline Nitrogênio & & & & & & \\
\hline $\begin{array}{l}\text { Amoniacal } \\
\text { (mg/L) } \mathrm{NH}_{4}\end{array}$ & 38,00 & 45,00 & 41,50 & 4,00 & 7,00 & 5,50 \\
\hline $\begin{array}{l}\text { Nitrogênio Total } \\
\text { (mg/L) }\end{array}$ & 210,00 & 644,00 & 427,00 & 994,00 & 1335,60 & 1164,80 \\
\hline $\begin{array}{c}\text { Cálcio } \\
\text { (mg/L) Ca }\end{array}$ & 675,00 & 1350,00 & 1012,50 & 1600,00 & 1450,00 & 1525,00 \\
\hline $\begin{array}{l}\text { Fosfato } \\
\text { (mg/L) }\end{array}$ & 427,10 & 561,54 & 494,32 & 408,05 & 532,56 & 470,31 \\
\hline $\begin{array}{l}\text { Sulfato } \\
\text { (mg/L) }\end{array}$ & 1300,00 & 1650,00 & 1475,00 & 5700,00 & 4400,00 & 5050,00 \\
\hline $\begin{array}{l}\text { Potássio } \\
\left(\mathrm{Kg} / \mathrm{m}^{3}\right) \mathrm{K}_{2} \mathrm{O}\end{array}$ & 2,79 & 2,98 & 2,89 & 6,90 & 6,70 & 6,80 \\
\hline $\begin{array}{l}\text { Magnésio } \\
\text { (mg/L) Mg }\end{array}$ & 250,00 & 300,00 & 275,00 & 1150,00 & 1150,00 & 1150,00 \\
\hline $\begin{array}{c}\text { Sódio } \\
\text { (mg/L) } \mathrm{Na}\end{array}$ & 375,00 & 400,00 & 387,50 & 250,00 & 275,00 & 262,50 \\
\hline
\end{tabular}

Fonte: Análises realizadas no Laboratório IBRA. Onde: Média (1) é a média aritmética dos parâmetros da vinhaça in natura e Média (2) é a média aritmética dos parâmetros da vinhaça concentrada.

\section{RESULTADOS E DISCUSSÃO}

\subsection{Efeitos na produtividade e qualidade da matéria prima pela aplicação de vinhaça}

$\mathrm{Na}$ tabela 2 são apresentados os resultados de produtividade de colmos (TCH), as análises tecnológicas, que foram avaliadas em outubro de 2013 (Tabelas 2 e 3). Tais resultados foram submetidos à análise estatística, o que permitiu classificar o comportamento da planta em cada tratamento aplicado. Observou-se maiores produtividades para T2 - Vinhaça in natura (120 m³/ha) mais Ureia (60 Kg/ha), T3 Vinhaça concentrada (20 m³/ha), T4 - Ureia (200 kg/ha), em que a cana-de-açúcar foi tratada com vinhaça e/ou fertilizante nitrogenado. 
A produtividade para T5 (testemunha) foi a menor, pois nenhum nutriente foi aplicado. Entretanto para T1 (Vinhaça in natura - $120 \mathrm{~m}^{3} / \mathrm{ha}$ ), verificou-se uma produtividade menor do que as encontradas para T2, T3 e T4. As doses de $\mathrm{N}$ dos tratamentos foram: T1 = 5,12 g.m-2, T2 = 7,76 g.m $\mathrm{m}^{-2}$, T3 = 2,32 g.m $\mathrm{m}^{-2}, \mathrm{~T} 4=8,80 \mathrm{~g} \cdot \mathrm{m}^{-2} \mathrm{e}$ T5 (zero), o fato da menor quantidade de nitrogênio total, podem explicar os resultados em comparação aos tratamentos T2 e T4, mas para T3 a diferença em relação a T1 está na forma de aplicação da Vinhaça, ou seja, in natura para T1 e concentrada para T3, já que em termos de N, o tratamento T3 recebeu menor quantidade o que sugere vantagem para o uso de vinhaça concentrada. Os resultados apresentados na tabela 2 estão dentro dos valores encontrados em canaviais comerciais de alta produtividade, exceto o tratamento controle, cuja produtividade foi próxima de 71,3 $\mathrm{TCH}$.

Tabela 2- Resultados de produtividade e análises tecnológicas da matéria prima nos diferentes tratamentos na colheita do experimento

\begin{tabular}{cccccccc}
\hline Trat. & TCH & Pol & Brix & Fibra & ATR & Tpol/ha & TAH \\
\hline T1 & $105,84 \mathrm{~b}$ & $18,59 \mathrm{a}$ & $21,30 \mathrm{a}$ & $13,38 \mathrm{a}$ & $152,90 \mathrm{a}$ & $16,25 \mathrm{~b}$ & $16,17 \mathrm{~b}$ \\
T2 & $135,94 \mathrm{a}$ & $18,67 \mathrm{a}$ & $21,20 \mathrm{a}$ & $13,62 \mathrm{a}$ & $152,64 \mathrm{a}$ & $20,88 \mathrm{a}$ & $20,74 \mathrm{a}$ \\
T3 & $132,21 \mathrm{a}$ & $18,23 \mathrm{a}$ & $20,87 \mathrm{a}$ & $13,18 \mathrm{a}$ & $150,47 \mathrm{a}$ & $19,99 \mathrm{a}$ & $19,90 \mathrm{a}$ \\
T4 & $130,19 \mathrm{a}$ & $18,64 \mathrm{a}$ & $21,27 \mathrm{a}$ & $14,10 \mathrm{a}$ & $151,73 \mathrm{a}$ & $19,85 \mathrm{a}$ & $19,80 \mathrm{a}$ \\
T5 & $71,30 \mathrm{c}$ & $19,78 \mathrm{a}$ & $22,08 \mathrm{a}$ & $13,15 \mathrm{a}$ & $162,41 \mathrm{a}$ & $11,69 \mathrm{c}$ & $11,57 \mathrm{c}$ \\
DSM & 9,29 & 2,44 & 2,50 & 1,52 & 18,44 & 2,83 & 2,72 \\
Prob.>F & $0,001^{\star *}$ & 0,362 & 0,55 & 0,35 & 0,33 & $0,001^{* *}$ & $0,001^{\star *}$
\end{tabular}

$\mathrm{TCH}$ - Tonelada de colmos por hectare; Pol - Porcentagem em massa de sacarose aparente contida no caldo; Brix - Porcentagem em massa de sólidos solúveis contidos no caldo; Fibra - Porcentagem de matéria seca insolúvel no caldo; ATR - Açúcares totais redutores (glicose e frutose, principalmente); Tpol/ha - toneladas de Pol por hectare; TAH - Tonelada de açúcar por hectare. Médias seguidas pela mesma letra, não diferem entre si, pelo teste de Tukey a $5 \%$ de probabilidade, no teste $\mathrm{F}$.

Considerando as análises tecnológicas da cana, a Tabela 2 mostra que para produtividade de sacarose aparente (Tpol/ha) e de açúcar (TAH) na colheita houve diferenças significativas nos valores obtidos na comparação entre os tratamentos, onde T1 resultou em valores significativamente menores que T2, T3 e T4, e T5 (testemunha) resultou em valores significativamente menores que T1, T2, T3 e T4. Essa informação é importante por mostrar a necessidade de complementação com $\mathrm{N}$ ao manejo da cana quando se dá com vinhaça in natura e também que o manejo com vinhaça concentrada resulta em valores semelhantes a vinhaça in natura mais $\mathrm{N}$ via ureia, bem como como adubação somente com ureia. 
Tabela 3- Resultados de análises tecnológicas para qualidade da cana de açúcar para diferentes tratamentos, no início (E1), meio (E2) e final de safra (E3)

\begin{tabular}{cccccccccccccccc}
\hline Trat. & \multicolumn{3}{c}{ Pol } & \multicolumn{4}{c}{ Brix } & \multicolumn{4}{c}{ Pureza } & \multicolumn{3}{c}{ Fibra } & \multicolumn{4}{c}{ ATR } \\
\hline & E1 & E2 & E3 & E1 & E2 & E3 & E1 & E2 & E3 & E1 & E2 & E3 & E1 & E2 & E3 \\
\hline T1 & 9,9 & 17,2 & 18,6 & 13,4 & $20.2 a b$ & 21,3 & 73,7 & 86,9 & 87,3 & 9,9 & 9,5 & 13,4 & 91,4 & 149,8 & 152,9 \\
T2 & 10,1 & 16,8 & 18,7 & 13,7 & $20,5 a b$ & 21.2 & 73,6 & 84,0 & 88,0 & 9,7 & 9,9 & 13,6 & 93,7 & 146,5 & 152,6 \\
T3 & 10,4 & 17,5 & 18,2 & 13,9 & $19,8 a b$ & 20.9 & 74,8 & 85,9 & 87,3 & 10,3 & 10,0 & 13,2 & 95,1 & 151,3 & 150,5 \\
T4 & 10,0 & 18,0 & 18,6 & 13,9 & $21,2 a$ & 21,3 & 71,9 & 88,7 & 87,8 & 10,8 & 10,8 & 14,1 & 92,8 & 152,7 & 151,1 \\
T5 & 10,4 & 16,9 & 19,8 & 14,0 & $19,2 b$ & 22,1 & 74,0 & 81,8 & 89,6 & 10,4 & 10,4 & 13,1 & 95,3 & 146,1 & 164,4 \\
DSM & 1,9 & 3,10 & 2,42 & 1,44 & 1,81 & 2,51 & 6,70 & 9,11 & 2,50 & 0,90 & 1,38 & 1,50 & 13,1 & 21,7 & 18.4 \\
Prob.>F & 0,71 & 0,62 & 0,41 & 0,76 & $0,02 *$ & 0,61 & 0,61 & 0,40 & 0,14 & 0,72 & 0,14 & 0,31 & 0,70 & 0,71 & 0,32 \\
\hline
\end{tabular}

T1: $120 \mathrm{~m}^{3} / \mathrm{ha}$ vinhaça in natura, T2: $20 \mathrm{m3} /$ ha vinhaça $+60 \mathrm{~kg}$ de ureia, T3: $20 \mathrm{~m} 3 / \mathrm{ha}$ vinhaça concentrada, T4 :200 Kg ureia/ha, T5: Testemunha. Medias seguida pela mesma letra não diferem entre si pelo teste de Tukey a 5\% de probabilidade. Épocas: início - abril (E1), meio - (E2) e final de safra (E3). .Não houve diferença entre médias de Brix, pol, Pureza e fibra e ATR, entre tratamentos pelo teste de Tukey a $5 \%$ de probabilidade.

Já na comparação entre as três épocas avaliadas (Tabela 3), as análises tecnológicas mostraram que para POL, PUREZA, FIBRA e ATR, dentro de cada época, não houve diferenças significativas entre os valores obtidos no caldo. No caso do BRIX, na época E2, a testemunha apresentou valor significativamente inferior ao nível de $5 \%$ de probabilidade em relação ao tratamento $\mathrm{T} 4$, mas iguais aos demais tratamentos (Tabela 3).

\subsection{Efeitos na fertilidade do solo e na nutrição da cultura}

Analisando os dados tecnológicos da cana ao longo da safra, expressos na tabela 3, notam-se diferenças significativas nos dados entre épocas, não houve diferença para maturação da cana de açúcar (pol, pureza ou umidade) entre tratamentos e nem na concentração de nitrogênio total no colmo ( $\mathrm{g} / \mathrm{kg})$ (Tabela 4), na ordem de: T1 $(0,345)$, T4 $(0,342)$, T3 $(0,337)$, T5 $(0,317)$ e T2 $(0,282)$, o que refletiu em uma exportação proporcional a produtividade.

Para os resultados de nitrogênio no caldo nos diferentes tratamentos, conforme a tabela 4, não houve diferenças significativas entre tratamentos, apenas entre as épocas, representando o inicio (E1), meio (E2) e o final (E3) da safra, sendo que E1 mensurado aos 180 DAC (dias após o corte), E2 aos 300 DAC e E3 aos 330 DAC. Observamos que da primeira (inicio da safra) para a segunda época houve um elevado aumento do nutriente no caldo. 
Tabela 4- Análises para teor de potássio no caldo (mg/L), em função dos tratamentos, no inicio (E1), meio (E2) e final de safra (E3)

\begin{tabular}{ccccccc}
\hline \multirow{2}{*}{ Trat. } & \multicolumn{3}{c}{$\mathbf{N}$} & & \multicolumn{3}{c}{$\mathbf{K}$} \\
\cline { 2 - 7 } & E1 & E2 & E3 & E1 & E2 & E3 \\
\hline T1 & 0,35 & 1,84 & 1,59 & 1,19 & $1,99 \mathrm{a}$ & $1,35 \mathrm{ab}$ \\
T2 & 0,28 & 1,78 & 1,51 & 1,28 & $1,94 \mathrm{a}$ & $1,48 \mathrm{ab}$ \\
T3 & 0,34 & 1,67 & 1,52 & 1,37 & $1,84 \mathrm{a}$ & $1,68 \mathrm{a}$ \\
T4 & 0,34 & 1,88 & 1,42 & 1,45 & $1,09 \mathrm{~b}$ & $1,04 \mathrm{~b}$ \\
T5 & 0,32 & 1,78 & 1,36 & 1,37 & $1,43 \mathrm{ab}$ & $1,03 \mathrm{~b}$ \\
DMS & 0,08 & 0,54 & 0,28 & 0,62 & 0,73 & 0,60 \\
Prob.>F & 0,23 & 0,19 & 0,17 & 0,23 & 0,04 & 0,25 \\
\hline
\end{tabular}

$\mathrm{T}_{1:} 120 \mathrm{~m}^{3} / \mathrm{ha}$ vinhaça in natura, $\mathrm{T}_{2}: 20 \mathrm{~m}^{3} / \mathrm{ha}$ de vinhaça $+60 \mathrm{~kg}$ de ureia, $\mathrm{T}_{3}: 20 \mathrm{~m}^{3} / \mathrm{ha}$ vinhaça concentrada, $T_{4}: 200 \mathrm{Kg}$ ureia/ha, $T_{5}$ : Testemunha. Medias seguida pela mesma letra não diferem entre si pelo teste de Tukey a $5 \%$ de probabilidade.

No caso do potássio observando-se as diferenças a partir da segunda época, entre os tratamentos que receberam à aplicação da vinhaça foram os que apresentaram diferenças (Tabela 4), ou seja, maiores teores. A exportação de nitrogênio total por hectare $(\mathrm{kg} \mathrm{N} / \mathrm{ha})$ foram por tratamento de: T3 $(92,2 \mathrm{~kg} / \mathrm{ha}), \mathrm{T} 4(89,3), \mathrm{T} 2$ $(76,0)$, T1 $(74,1)$ e T5 $(45,5)$. Os resultados de acumulação de N no caldo teve relacionamento com a melhoria da fertilidade do solo e na maior disponibilidade de nitrato e de amônio no solo após a adição de tratamento, que estão expressos na dinâmica de disponibilidade de N-nitrato e N- amônio, o que será tratado mais adiante no texto, em uma análise ambiental.

Quanto à questão dos efeitos dos tratamentos na alteração da fertilidade do solo (Tabela 5), houveram coletas de amostras de solo que foram realizadas no quarto mês após o corte, e os resultados foram separados em tratamentos, posição, profundidade e nutrientes. Tais resultados de fertilidade do solo na profundidade de 0-20 cm, nota-se diferença estatística para a concentração de Mg na posição EL (entrelinhas). A concentração determinada no tratamento T4 (Ureia) foi significativamente menor do que nos outros tratamentos nessa posição, mas na amostragem realizada na linha de plantio não houve diferença estatística. Isso ocorreu devido a vinhaça carregar o Mg em sua composição, e mesmo apresentando uma concentração cinco vezes menor na vinhaça in natura, a dose cinco vezes maior proporcionou similaridade entre os diferentes tratamentos com vinhaça (Tabela 5).

O potássio possui elevada concentração na vinhaça, promovendo diferenças 
entre tratamentos na posição linha (L) (Tabela 5). Neste caso, novamente, os tratamentos T4 (Uréia) e T5 (Testemunha), que não receberam vinhaça, apresentaram as menores concentrações, enquanto que o T3 (Vinhaça concentrada) apresentou a maior média, porém não sendo estatisticamente diferente dos demais tratamentos que receberam a vinhaça. Na profundidade de 20-40 cm para $\mathrm{Mg}$ houve diferença estatística para a posição L, tendo T2 e T5 os menores teores. Quanto ao potássio a essa profundidade houve apenas diferença para a posição EL tendo T1, T2, T4 e T5 menores teores em relação ao T3. Como no passado a área experimental estava em produção, a adição de fertilizantes em sua totalidade pode ter diminuído a importância dos tratamentos com vinhaça para camadas mais profundas. Em função disso, na profundidade de 40-60 cm ocorreu diferença significativa apenas para $\mathrm{Mg}$, sendo que para a posição "L" T1 apresentou o maior teor, e T4 o menor. Para a posição EL, T2 e T3 tiveram maiores teores, enquanto que T4 o menor (Tabela 5).

$\mathrm{O} \mathrm{pH}$ do solo mostrou-se bastante estável ao longo do tempo e entre os tratamentos, variando na faixa de 5 à 5,6. Somente aos 60 a 78 dias, para os tratamentos que receberam a vinhaça, houve diferença significativa, o que está de acordo com dados de Mattiazzo e Gloria $(1985,1987)$. Em função do pH ácido da vinhaça, é possível levantar a hipótese de que seu uso na agricultura viesse a comprometer a qualidade do solo, principalmente elevando sua acidez. Entretanto Almeida et. al. (1952), observaram que, apesar da vinhaça ser ácida, ao contrário do que se esperava, no médio prazo ela elevava o pH do solo, melhorando a sua acidez e suas propriedades físicas. Após sua aplicação no solo, a vinhaça promove reações biológicas de natureza redutora que consomem prótons e fazem com que o $\mathrm{pH}$ se eleve (ROSSETTO, 1987; MATTIAZZO; GLORIA, 1985 e 1987).

Os resultados mostram que a aplicação de vinhaça concentrada permitiu benefícios na fertilidade do solo, especialmente em relação ao $\mathrm{K}$ e Mg, de forma similar à vinhaça "in natura", partindo-se do princípio de que as diferenças nas doses compensaram as diferenças de concentração entre os dois produtos.

Para os dados de fertilidade do solo temos as principais diferenças significativas, como se observa na Figura 1, onde temos o teor de $\mathrm{K}$ de 2 tratamentos distintos em relação à posição e profundidade. 
Tabela 5- Resultados de fertilidade do solo, aos 4 meses, após aplicação dos tratamentos

\begin{tabular}{|c|c|c|c|c|c|c|c|}
\hline \multirow{3}{*}{ Trat. } & \multirow{3}{*}{ Posição } & \multicolumn{6}{|c|}{ Profundidade 0-20 } \\
\hline & & Al & $\mathbf{C a}$ & Mg & $\mathbf{K}$ & $\mathbf{P}$ & $\mathbf{p H}$ \\
\hline & & & cmolc/d & $\longrightarrow$ & mg/L & $\longrightarrow$ & \\
\hline \multirow{2}{*}{$\mathbf{T 1}$} & $\mathbf{L}$ & 0,05 & 3,02 & $0,99 a$ & $74,83 \mathrm{ab}$ & 2,39 & 5,50 \\
\hline & EL & 0,03 & 2,99 & $1,05 \mathrm{a}$ & 71,33 a & 1,96 & 5,77 \\
\hline \multirow{2}{*}{$\mathbf{T 2}$} & $\mathbf{L}$ & 0,05 & 2,98 & 0,99 a & $76,00 \mathrm{ab}$ & 3,23 & 5,45 \\
\hline & EL & 0,03 & 2,83 & $0,99 \mathrm{ab}$ & 48,17 a & 2,22 & 5,53 \\
\hline \multirow{2}{*}{ T3 } & $\mathbf{L}$ & 0,06 & 2,57 & 0,95 a & 97,00 a & 2,60 & 5,46 \\
\hline & EL & 0,32 & 2,87 & $1,05 \mathrm{a}$ & 69,67 a & 2,37 & 5,49 \\
\hline \multirow{2}{*}{$\mathbf{T 4}$} & $\mathbf{L}$ & 0,06 & 2,88 & $0,89 \mathrm{a}$ & $50,67 \mathrm{~b}$ & 4,13 & 5,40 \\
\hline & EL & 0,07 & 2,70 & $0,85 \mathrm{~b}$ & 32,17 a & 2,55 & 5,55 \\
\hline \multirow{2}{*}{$\mathbf{T 5}$} & $\mathbf{L}$ & 0,04 & 3,04 & 0,99 a & $45,83 \mathrm{~b}$ & 3,49 & 5,45 \\
\hline & EL & 0,02 & 3,20 & $1,05 \mathrm{a}$ & 30,50 a & 2,65 & 5,61 \\
\hline \multirow{3}{*}{ Trat. } & \multirow{3}{*}{ Posição } & \multicolumn{6}{|c|}{ Profundidade 20-40 } \\
\hline & & Al & Ca & Mg & $\mathbf{K}$ & $\mathbf{P}$ & pH \\
\hline & & & cmolc/d & 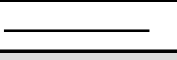 & mg/L & $\bar{C}$ & \\
\hline \multirow{2}{*}{$\mathbf{T 1}$} & $\mathbf{L}$ & 0,10 & 2,50 & $1,01 \mathrm{a}$ & 35,83 a & 1,91 & 5,48 \\
\hline & EL & 0,18 & 2,50 & $0,81 \mathrm{a}$ & $14,17 \mathrm{~b}$ & 1,30 & 5,39 \\
\hline \multirow{2}{*}{$\mathbf{T 2}$} & $\mathbf{L}$ & 0,25 & 2,20 & $0,75 b$ & 30,20 a & 2,31 & 5,08 \\
\hline & EL & 0,23 & 2,18 & $0,75 \mathrm{a}$ & $14,03 \mathrm{~b}$ & 2,02 & 5,10 \\
\hline \multirow{2}{*}{ T3 } & $\mathbf{L}$ & 0,23 & 2,10 & $0,83 \mathrm{ab}$ & $22,33 \mathrm{a}$ & 1,33 & 5,08 \\
\hline & EL & 0,20 & 2,11 & $0,76 \mathrm{a}$ & 23,67 a & 1,51 & 5,08 \\
\hline \multirow{2}{*}{ T4 } & $\mathbf{L}$ & 0,16 & 2,61 & $0,83 a b$ & 21,20 a & 2,83 & 5,28 \\
\hline & EL & 0,35 & 2,21 & $0,78 \mathrm{a}$ & $14,67 \mathrm{ab}$ & 1,33 & 4,98 \\
\hline \multirow{2}{*}{$\mathbf{T 5}$} & $\mathbf{L}$ & 0,17 & 2,31 & $0,72 \mathrm{~b}$ & $15,20 \mathrm{a}$ & 1,65 & 5,14 \\
\hline & EL & 0,21 & 2,35 & $0,75 \mathrm{a}$ & $13,00 \mathrm{~b}$ & 1,43 & 5,24 \\
\hline \multirow{3}{*}{ Trat. } & \multirow{3}{*}{ Posição } & \multicolumn{6}{|c|}{ Profundidade 40-60 } \\
\hline & & Al & Ca & Mg & $\mathbf{K}$ & $\mathbf{P}$ & pH \\
\hline & & & $\mathrm{cmolc} / \mathrm{d}$ & 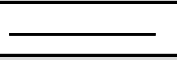 & mg/L & 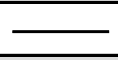 & \\
\hline \multirow{2}{*}{$\mathbf{T 1}$} & $\mathbf{L}$ & 0,4 & 2,04 & $1,03 \mathrm{a}$ & 32,83 & 1,23 & 5,18 \\
\hline & EL & 0,38 & 1,92 & $0,75 \mathrm{a}$ & 26,17 & 2,18 & 5,04 \\
\hline \multirow{2}{*}{$\mathbf{T 2}$} & $\mathbf{L}$ & 0,56 & 1,6 & $0,75 \mathrm{ab}$ & 16,5 & 1,54 & 4,99 \\
\hline & EL & 0,4 & 1,85 & $0,82 \mathrm{a}$ & 16 & 1,09 & 5,14 \\
\hline \multirow{2}{*}{ T3 } & $\mathbf{L}$ & 0,67 & 1,32 & $0,74 \mathrm{ab}$ & 13,83 & 1,6 & 4,85 \\
\hline & EL & 0,78 & 1,32 & $0,64 \mathrm{a}$ & 15,17 & 1,08 & 4,82 \\
\hline \multirow{2}{*}{ T4 } & $\mathbf{L}$ & 0,79 & 1,41 & $0,56 \mathrm{~b}$ & 14,83 & 1,56 & 4,87 \\
\hline & EL & 0,78 & 1,34 & $0,53 \mathrm{a}$ & 10 & 1,23 & 4,77 \\
\hline \multirow{2}{*}{$\mathbf{T 5}$} & $\mathbf{L}$ & 0,39 & 1,84 & $0,74 \mathrm{ab}$ & 25,5 & 1,64 & 5,04 \\
\hline & EL & 0,52 & 1,72 & 0,69 a & 11,5 & 1,15 & 4,97 \\
\hline
\end{tabular}

Médias seguidas pela mesma letra, não diferem entre si, pelo teste de Tukey a $5 \%$ de probabilidade. T1: $120 \mathrm{m3} / \mathrm{ha}$ vinhaça in natura, T2: $20 \mathrm{~m} 3 / \mathrm{ha}$ vinhaça + $60 \mathrm{~kg}$ de ureia, T3: $20 \mathrm{~m} 3 / \mathrm{ha}$ vinhaça concentrada, T4 :200 Kg ureia/ha, T5: Testemunha. 
Figura 1 - Disponibilidade de potássio no solo em diferentes profundidades no perfil nos distintos tratamentos com vinhaça

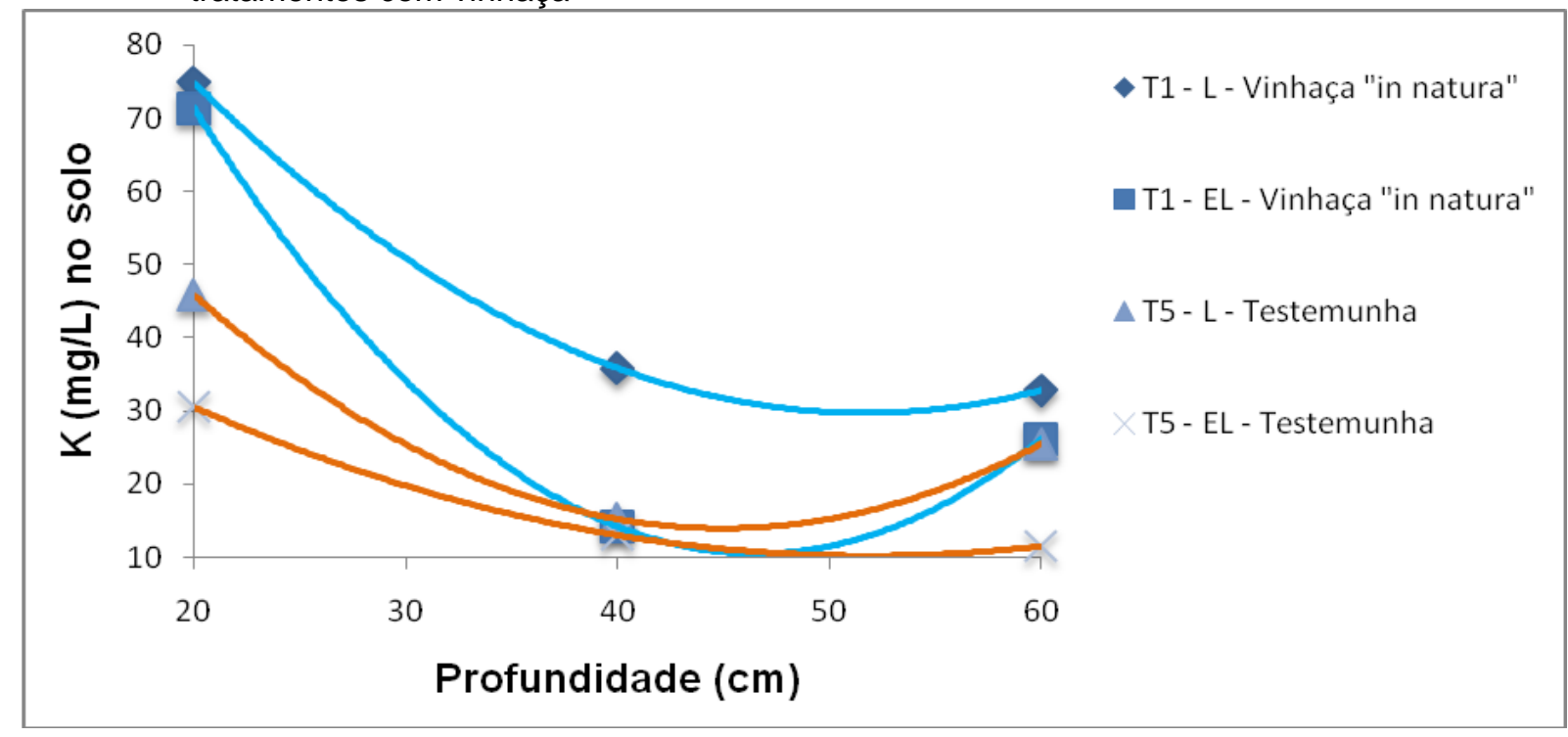

\subsection{Efeito dos tratamentos na nutrição da cultura}

Para o tratamento T1 (Vinhaça "in natura") entre posições temos uma grande diferença na profundidade de $40 \mathrm{~cm}$, visto ser maior o efeito residual do $\mathrm{K}$ na linha da cana-planta. Observando os dados encontrados na fertilidade do solo (Tabela 5) e no diagnóstico foliar coletados aos quatro meses após o corte, em relação aos resultados de teores de N, P e K encontrados nos tratamentos aplicados na tabela 6. Pode se observar que no caso do nitrogênio, não houve diferença na quantidade do nutriente encontrada nos tratamentos na análise foliar, entretanto na tabela 6 segundo Malavolta et al. (1997), o nível de suficiência de nitrogênio na interpretação foliar em cana-soca seria de 2,0 a 2,2 \%, mas segundo Silva, (2009), temos níveis de 1,8 a $2,5 \%$, isso demonstra uma leve deficiência do elemento na planta, independente do tratamento aplicado.

No caso do fósforo temos uma pequena variação para os tratamentos, sendo que para os tratamentos T1 e T2 houve uma diferença significativa à 5\%, outros tratamentos não apresentaram diferenças significativas, sendo que o T2 alcançou maiores valores do nutriente, porém segundo Malavolta, (1997) e Silva, (2009), temos uma deficiência considerável de fósforos já que os autores sugerem valores na faixa de 2,0 a 2,4 g/kg e 1,5 a 3,0 g/kg respectivamente, entretanto Haag, (1978), encontrou valores de suficiência de $P$ entre 1,1 a 1,6 g/kg. 
Tabela 6- Diagnose foliar em amostras coletados da folha +1 da soqueira, cultivas nos diferentes tratamentos, aos quatro meses após corte.

\begin{tabular}{|c|c|c|c|}
\hline \multirow{3}{*}{ Trat. } & \multicolumn{2}{|c|}{ Análise foliar +1 } & \multirow[b]{2}{*}{$\mathbf{K}$} \\
\hline & $\mathbf{N}$ & $\mathbf{P}$ & \\
\hline & $\%$ & & \\
\hline T1 & 1,58 & $1,17 \mathrm{~b}$ & $11,76 a b$ \\
\hline $\mathrm{T} 2$ & 1,65 & $1,30 \mathrm{a}$ & $11,58 a b$ \\
\hline T3 & 1,64 & $1,24 a b$ & $12,21 \mathrm{a}$ \\
\hline T4 & 1,62 & $1,26 a b$ & $10,71 \mathrm{~b}$ \\
\hline T5 & 1,62 & $1,23 a b$ & $10,79 \mathrm{~b}$ \\
\hline DMS & 0,12 & 0,10 & 1,38 \\
\hline Valor $\mathrm{F}$ & 1,84 & 3,09 & 2,13 \\
\hline Prob. $>\mathrm{F}$ & 0,12 & 0,02 & 0,07 \\
\hline CV (\%) & 4,42 & 4,70 & 7,00 \\
\hline
\end{tabular}

$\mathrm{T}_{\text {1: }} 120 \mathrm{~m}^{3} / \mathrm{ha}$ vinhaça in natura, $\mathrm{T}_{2}: 20 \mathrm{~m}^{3} / \mathrm{ha}$ vinhaça $+60 \mathrm{~kg}$ de ureia, $\mathrm{T}_{3}: 20 \mathrm{~m}^{3} / \mathrm{ha}$ vinhaça concentrada, $\mathrm{T}_{4}: 200 \mathrm{Kg}$ ureia/ha, $\mathrm{T}_{5}:$ Testemunha. Medias seguida pela mesma letra não diferem entre si pelo teste de Tukey a $5 \%$ de probabilidade.

Para potássio se verificou variações significativas, por conta de ser o nutriente exportado em maior quantidade pela cultura, o tratamento T3, o qual se aplicou vinhaça concentrada apresentou maior teor em relação aos tratamentos 4 e 5 que são respectivamente uréia e testemunha, segundo Silva (2009), valores entre 10 a 16 $\mathrm{g} / \mathrm{kg}$ de K, conforme o esperado. De acordo com estudos de Haag (1965) e de Haag e Accorsi (1978), em condições controladas de solução nutritiva para aparecimento no campo de deficiência visual as concentrações foliar seriam de $<0,6 \%$ de $\mathrm{N}$, de $<$ $0,5 \mathrm{~g} / \mathrm{kg}$ de $\mathrm{P}$ e de $7,5 \mathrm{~g} / \mathrm{kg}$ de $\mathrm{K}$.

\subsection{Análise ambiental: efeitos nas variações no N-disponível e carbono solúvel do solo no tempo pela aplicação de vinhaça e de $\mathrm{N}$-fertilizante}

Analisando-se o efeito dos tratamentos com fertilização nitrogenada e vinhaça $\left(T_{1}, T_{2}, T_{3}, T_{4}\right)$, em comparação a testemunha $\left(T_{5}\right)$, sobre a disponibilidade de nitrato $\left(\mathrm{NO}_{3}-\right)$ no solo em cada fase do cultivo da cana (Tabela 7 ), observou-se que somente nos tratamentos com uréia as concentrações foram um pouco mais altas. Quatro dias após o início do estudo, os níveis de $\mathrm{NO}_{3}{ }^{-}$foram reduzidos em todos os tratamentos e novamente se elevaram no sexto dia. A partir daí as condições de umida- 
de do solo eram maiores e perdas por desnitrificação explicariam uma nova redução da concentração de $\mathrm{NO}_{3}{ }^{-}$no solo (Tabela 7).

Já a concentração de $\mathrm{NH}^{+}{ }^{+}$no solo foi mais elevada no tratamento com uréia sem vinhaça, indicando que perdas maiores no tratamento em que a mesma dose de uréia foi aplicada com a vinhaça ocorreram (Tabela 8). No entanto, não é claro como uma interação entre uréia, de reação alcalina no solo, e vinhaça, de caráter ácido, poderiam resultar em perdas de $\mathrm{N}$ do solo. É possível, porém, que tenha havido nitrificação e em seguida desnitrificação até $\mathrm{N}_{2}$, promovida pela alta concentração de C lábil (SMITH et al., 2003) no tratamento com uréia e vinhaça (Tabela 8).

Na comparação de médias de tratamentos para carbono solúvel verificaramse maiores valores na vinhaça concentrada (T3), aos 8, 22, 3035 e 209 dias após aplicação. No entanto, de modo geral, houve forte tendência de maior concentração de C solúvel quando vinhaça foi aplicada ao solo (Tabela 9), o que respaldaria a hipótese de potencial de redução do solo e elevação do pH e de maiores perdas de $\mathrm{N}$ por desnitrificação em função da aplicação da vinhaça junto com a ureia.

Tabela 7 - Influência dos tratamentos nos teores de nitrato (N-NO3) em: (mg/kg) do solo nas diferentes épocas, após aplicação dos tratamentos

\begin{tabular}{|c|c|c|c|c|c|c|c|}
\hline \multirow{2}{*}{$\begin{array}{l}\text { Época (Dap) } \\
\text { Épocas }\end{array}$} & \multicolumn{5}{|c|}{ Tratamentos $(\mathrm{mg} / \mathrm{kg})$} & \multicolumn{2}{|c|}{ Estatística } \\
\hline & $\mathrm{T}_{1}$ & $\mathrm{~T}_{2}$ & $T_{3}$ & $\mathbf{T}_{4}$ & $T_{5}$ & $\operatorname{Pr}>\mathrm{F}$ & DSM \\
\hline 1 & $3,20 \mathrm{~B}$ & $10,95 \mathrm{AB}$ & $0,26 \mathrm{~B}$ & $15,66 \mathrm{~A}$ & $3,90 \mathrm{~B}$ & 0,0067 & 10,915 \\
\hline 4 & $2,51 \mathrm{~A}$ & $3,85 \mathrm{~A}$ & $2,18 \mathrm{~A}$ & $5,45 \mathrm{~A}$ & $4,56 \mathrm{~A}$ & 0,7220 & 9 \\
\hline 6 & $5,01 \mathrm{~A}$ & $17,50 \mathrm{~A}$ & $4,41 \mathrm{~A}$ & $12,32 \mathrm{~A}$ & $6,08 \mathrm{~A}$ & 0,4246 & 26,601 \\
\hline 8 & $4,00 \mathrm{BC}$ & $9,83 \mathrm{~A}$ & $2,66 \mathrm{C}$ & $4,80 \mathrm{~B}$ & $4,41 \mathrm{BC}$ & $<, 0001$ & 1,789 \\
\hline 12 & $4,37 \mathrm{~B}$ & $6,18 \mathrm{~B}$ & $5,41 \mathrm{~B}$ & $10,53 \mathrm{~A}$ & $4,08 \mathrm{~B}$ & 0,0029 & 3,950 \\
\hline 22 & $1,89 \mathrm{~A}$ & $12,15 \mathrm{~A}$ & $2,31 \mathrm{~A}$ & $1,77 \mathrm{~A}$ & $2,01 \mathrm{~A}$ & 0,3330 & 19,155 \\
\hline 30 & $1,06 \mathrm{~A}$ & $2,15 \mathrm{~A}$ & $2,67 \mathrm{~A}$ & $3,35 \mathrm{~A}$ & $0,94 \mathrm{~A}$ & 0,5129 & 5,352 \\
\hline 35 & $1,24 \mathrm{~A}$ & $9,99 \mathrm{~A}$ & $2,05 \mathrm{~A}$ & $4,76 \mathrm{~A}$ & $2,05 \mathrm{~A}$ & 0,2920 & 14,432 \\
\hline 43 & $2,36 \mathrm{~A}$ & $10,20 \mathrm{~A}$ & $4,07 \mathrm{~A}$ & $4,76 \mathrm{~A}$ & $3,70 \mathrm{~A}$ & 0,2006 & 10,668 \\
\hline 49 & $0,92 \mathrm{~A}$ & $1,77 \mathrm{~A}$ & $1,21 \mathrm{~A}$ & $3,96 \mathrm{~A}$ & $1,39 \mathrm{~A}$ & 0,6590 & 7,560 \\
\hline 57 & $5,30 A$ & $3,68 \mathrm{~A}$ & $3,91 \mathrm{~A}$ & $3,83 \mathrm{~A}$ & $4,93 \mathrm{~A}$ & 0,8850 & 6,823 \\
\hline 64 & $5,13 \mathrm{~A}$ & $1,62 \mathrm{~A}$ & $1,70 \mathrm{~A}$ & $1,14 \mathrm{~A}$ & $8,22 \mathrm{~A}$ & 0,2590 & 11,709 \\
\hline 71 & $1,78 \mathrm{~A}$ & $1,27 \mathrm{~A}$ & $2,26 \mathrm{~A}$ & $1,14 \mathrm{~A}$ & $4,76 \mathrm{~A}$ & 0,2080 & 5,278 \\
\hline 78 & $0,62 \mathrm{C}$ & $4,27 \mathrm{C}$ & $11,54 \mathrm{~B}$ & $1,11 \mathrm{C}$ & $22,11 \mathrm{~A}$ & $<, 0001$ & 5,131 \\
\hline 106 & $2,72 \mathrm{~A}$ & $4,27 \mathrm{~A}$ & $4,16 \mathrm{~A}$ & $3,32 \mathrm{~A}$ & $4,33 \mathrm{~A}$ & 0,3603 & 4,094 \\
\hline 141 & $1,21 \mathrm{C}$ & $2,91 \mathrm{BC}$ & $4,77 \mathrm{AB}$ & $5,80 A$ & $6,62 \mathrm{~A}$ & 0,0003 & 2,422 \\
\hline 162 & $1,43 \mathrm{C}$ & $1,31 \mathrm{DC}$ & $1,25 \mathrm{D}$ & $1,85 \mathrm{~B}$ & $7,07 \mathrm{~A}$ & $<, 0001$ & 0,176 \\
\hline 204 & $0,27 \mathrm{C}$ & $1,13 \mathrm{~B}$ & $0,87 \mathrm{~B}$ & $2,26 \mathrm{~A}$ & $1,07 \mathrm{~B}$ & $<, 0001$ & 0,562 \\
\hline 209 & $2,64 \mathrm{~B}$ & $0,62 \mathrm{E}$ & $1,92 \mathrm{C}$ & $3,34 \mathrm{~A}$ & $1,09 \mathrm{D}$ & $<, 0001$ & 0,303 \\
\hline 245 & $0,93 C$ & $2,37 \mathrm{AB}$ & $1,61 \mathrm{BC}$ & $2,44 A B$ & $2,75 \mathrm{~A}$ & 0,0007 & 0,898 \\
\hline 294 & $1,20 \mathrm{~A}$ & $2,54 \mathrm{~A}$ & $3,36 \mathrm{~A}$ & $1,24 \mathrm{~A}$ & $1,15 \mathrm{~A}$ & 0,3021 & 4,071 \\
\hline 347 & $0,11 \mathrm{~B}$ & $0,92 \mathrm{~A}$ & $0,95 A$ & $0,95 A$ & $0,15 B$ & $<, 0001$ & 0,1156 \\
\hline
\end{tabular}


Onde: Dap: Dias após a coleta, $T_{1}: 120 \mathrm{~m}^{3} / \mathrm{ha}$ vinhaça in natura, $\mathrm{T}_{2}: 20 \mathrm{~m}^{3} / \mathrm{ha}$ vinhaça $+60 \mathrm{~kg}$ de ureia, $T_{3}: 20 \mathrm{~m}^{3} / \mathrm{ha}$ vinhaça concentrada, $\mathrm{T}_{4}: 200 \mathrm{Kg}$ ureia/ha, $\mathrm{T}_{5}$ : Testemunha. Medias seguida pela mesma letra não diferem entre si pelo teste de Tukey a $5 \%$ de probabilidade.

Tabela 8 - Influência das médias dos tratamentos nos teores de amônio ( $\mathrm{N}-\mathrm{NH} 4)$ do solo nas diferen tes épocas, no teste de Tukey, a 5\% de significância no teste $\mathrm{F}$

\begin{tabular}{|c|c|c|c|c|c|c|c|}
\hline \multirow{2}{*}{$\begin{array}{c}\text { Época } \\
\text { (Dap) }\end{array}$} & \multicolumn{5}{|c|}{ Tratamentos (mg/kg) } & \multicolumn{2}{|c|}{ Estatística } \\
\hline & $\mathrm{T}_{1}$ & $T_{2}$ & $T_{3}$ & $\mathbf{T}_{4}$ & $T_{5}$ & $\operatorname{Pr}>\mathrm{F}$ & DSM \\
\hline 1 & $4,89 \mathrm{~B}$ & $25,35 \mathrm{~B}$ & $0,61 B$ & $133,69 \mathrm{~A}$ & $5,69 \mathrm{~B}$ & 0,0001 & 54,532 \\
\hline 4 & $4,27 \mathrm{~A}$ & $29,17 \mathrm{~A}$ & $4,66 \mathrm{~A}$ & $47,10 \mathrm{~A}$ & $5,67 \mathrm{~A}$ & 0,3815 & 86,085 \\
\hline 6 & $8,45 \mathrm{~A}$ & $21,35 \mathrm{~A}$ & $6,89 \mathrm{~A}$ & $62,52 \mathrm{~A}$ & $4,14 \mathrm{~A}$ & 0,7761 & 91,22 \\
\hline 8 & $7,24 \mathrm{~A}$ & $2,66 \mathrm{~A}$ & $5,07 \mathrm{~A}$ & $2,60 \mathrm{~A}$ & $2,70 \mathrm{~A}$ & 0,4038 & 9,453 \\
\hline 12 & $16,68 \mathrm{~A}$ & $15,08 \mathrm{~A}$ & $17,36 \mathrm{~A}$ & $16,75 \mathrm{~A}$ & $17,27 \mathrm{~A}$ & 0,4288 & 6,865 \\
\hline 22 & $4,66 \mathrm{~A}$ & $3,47 \mathrm{~A}$ & $3,38 \mathrm{~A}$ & $6,64 \mathrm{~A}$ & $3,16 \mathrm{~A}$ & 0,3934 & 6,564 \\
\hline 30 & $4,73 \mathrm{~A}$ & $6,83 \mathrm{~A}$ & $7,29 \mathrm{~A}$ & $14,46 \mathrm{~A}$ & $5,02 \mathrm{~A}$ & 0,3613 & 17,234 \\
\hline 35 & $9,80 \mathrm{~A}$ & $6,23 \mathrm{~A}$ & $5,00 A$ & $7,54 \mathrm{~A}$ & $5,23 \mathrm{~A}$ & 0,1465 & 6,353 \\
\hline 43 & $12,98 \mathrm{~A}$ & $7,88 \mathrm{~A}$ & $8,76 \mathrm{~A}$ & $7,54 \mathrm{~A}$ & $10,97 \mathrm{~A}$ & 0,2330 & 8,519 \\
\hline 49 & $7,50 \mathrm{~A}$ & $5,16 \mathrm{AB}$ & $5,60 \mathrm{AB}$ & $6,70 \mathrm{AB}$ & $1,69 \mathrm{~B}$ & 0,0122 & 5,658 \\
\hline 57 & $7,01 \mathrm{~A}$ & $5,48 \mathrm{~A}$ & $6,51 \mathrm{~A}$ & $6,04 \mathrm{~A}$ & $7,04 \mathrm{~A}$ & 0,5990 & 6,621 \\
\hline 64 & $10,85 \mathrm{~A}$ & $11,10 \mathrm{~A}$ & $6,17 \mathrm{~A}$ & $6,30 \mathrm{~A}$ & $5,77 \mathrm{~A}$ & 0,2770 & 10,571 \\
\hline 71 & $0,00 \mathrm{~B}$ & $7,30 \mathrm{~A}$ & $5,22 \mathrm{~A}$ & $6,30 \mathrm{~A}$ & $1,22 B$ & $<, 0001$ & 2,164 \\
\hline 78 & $8,39 A$ & $6,04 \mathrm{~A}$ & $76,05 \mathrm{~A}$ & $3,91 \mathrm{~A}$ & $19,45 \mathrm{~A}$ & 0,3869 & 135,910 \\
\hline 106 & $6,40 \mathrm{~A}$ & $6,04 \mathrm{~A}$ & $5,39 \mathrm{~A}$ & $5,40 \mathrm{~A}$ & $4,72 \mathrm{~A}$ & 0,6489 & 3,972 \\
\hline 141 & $3,21 \mathrm{D}$ & $5,94 \mathrm{BC}$ & $5,71 \mathrm{C}$ & $8,28 \mathrm{~A}$ & $6,69 \mathrm{~B}$ & $<, 0001$ & 0,864 \\
\hline 162 & $3,24 \mathrm{~B}$ & $6,67 \mathrm{~A}$ & $6,99 A$ & $7,29 \mathrm{~A}$ & $6,69 \mathrm{~A}$ & $<, 0001$ & 1,098 \\
\hline 204 & $0,97 C$ & $6,04 \mathrm{~A}$ & $7,20 \mathrm{~A}$ & $7,27 \mathrm{~A}$ & $4,43 B$ & $<, 0001$ & 2,113 \\
\hline 209 & $8,77 \mathrm{~A}$ & $6,34 \mathrm{~B}$ & $7,51 \mathrm{AB}$ & $8,64 A B$ & $2,19 \mathrm{C}$ & $<, 0001$ & 2,350 \\
\hline 245 & $3,28 \mathrm{C}$ & $5,13 \mathrm{~A}$ & $4,44 A B$ & $4,06 \mathrm{BC}$ & $4,97 \mathrm{~A}$ & 0,0006 & 0,877 \\
\hline 294 & $5,71 \mathrm{~A}$ & $7,57 \mathrm{~A}$ & $5,24 A B$ & $2,00 B$ & $4,77 \mathrm{AB}$ & 0,0057 & 3,381 \\
\hline 347 & $1,17 \mathrm{~B}$ & $1,47 \mathrm{AB}$ & $1,36 \mathrm{~B}$ & $1,94 \mathrm{~A}$ & $1,36 \mathrm{~B}$ & 0,0106 & 0,537 \\
\hline
\end{tabular}

Onde: Dap: Dias após a coleta, T1: $120 \mathrm{m3} / \mathrm{ha}$ vinhaça in natura, T2: $20 \mathrm{~m}^{3} / \mathrm{ha}$ vinhaça $+60 \mathrm{~kg}$ de ureia, T3: $20 \mathrm{~m} 3 / \mathrm{ha}$ vinhaça concentrada, T4:200 Kg ureia/ha, T5: Testemunha. Medias seguida pela mesma letra não diferem entre si pelo teste de Tukey a 5\% de probabilidade. 
Tabela 9 - Influência das médias dos tratamentos nos teores de carbono solúvel do solo nas diferentes épocas, no teste de Tukey, a 5\% de significância no teste $\mathrm{F}$

\begin{tabular}{|c|c|c|c|c|c|c|c|}
\hline \multirow{2}{*}{$\begin{array}{c}\text { Época } \\
\text { Dap }\end{array}$} & \multicolumn{5}{|c|}{ Tratamentos (mg C kg-solo seco) } & \multicolumn{2}{|c|}{ Estatística } \\
\hline & $\mathrm{T}_{1}$ & $\mathrm{~T}_{2}$ & $T_{3}$ & $\mathrm{~T}_{4}$ & $T_{5}$ & $\operatorname{Pr}>\mathrm{F}$ & DSM \\
\hline 1 & $3,21 \mathrm{~B}$ & $10,95 \mathrm{AB}$ & $0,27 \mathrm{~B}$ & $15,66 \mathrm{~A}$ & $3,90 \mathrm{~B}$ & 0,0540 & 11,2955 \\
\hline 4 & $103,90 A$ & $140,33 A$ & $131,13 \mathrm{~A}$ & $95,23 \mathrm{~A}$ & $93,72 \mathrm{~A}$ & 0,1570 & 70,532 \\
\hline 6 & $119,77 \mathrm{~A}$ & $94,20 \mathrm{~A}$ & $128,73 \mathrm{~A}$ & $97,03 \mathrm{~A}$ & $93,50 \mathrm{~A}$ & 0,3330 & 69,197 \\
\hline 8 & $113,58 \mathrm{AB}$ & $105,87 A B$ & $119,43 \mathrm{~A}$ & $93,30 \mathrm{~B}$ & $93,60 \mathrm{~B}$ & 0,0260 & 25,732 \\
\hline 12 & $112,42 \mathrm{~A}$ & $89,63 \mathrm{~A}$ & $123,47 \mathrm{~A}$ & $118,32 \mathrm{~A}$ & $89,60 \mathrm{~A}$ & 0,3820 & 71,747 \\
\hline 22 & $112,42 \mathrm{~A}$ & $89,59 A B$ & $106,81 \mathrm{~A}$ & $88,47 \mathrm{AB}$ & $75,13 \mathrm{~B}$ & 0,0192 & 31,201 \\
\hline 30 & $116,21 \mathrm{~A}$ & $81,44 A B$ & $62,28 \mathrm{~B}$ & $105,60 \mathrm{~A}$ & $60,67 \mathrm{~B}$ & 0,0030 & 37,659 \\
\hline 35 & $102,67 \mathrm{~A}$ & $123,33 A$ & $112,53 \mathrm{~A}$ & $136,03 \mathrm{AB}$ & $106,07 \mathrm{~A}$ & 0,1470 & 43,970 \\
\hline 43 & $103,70 \mathrm{~A}$ & $98,20 A$ & $117,27 \mathrm{~A}$ & 107,97A & $92,07 \mathrm{~A}$ & 0,3430 & 40,867 \\
\hline 49 & $120.40 \mathrm{~A}$ & $80.80 \mathrm{~A}$ & $110.23 \mathrm{~A}$ & $111.00 \mathrm{~A}$ & $100.21 \mathrm{~A}$ & 0,6120 & 87,892 \\
\hline 57 & $109,27 \mathrm{~A}$ & $104,30 \mathrm{~A}$ & $107,67 \mathrm{~A}$ & $112,67 \mathrm{~A}$ & $89,97 \mathrm{~A}$ & 0,3420 & 37,493 \\
\hline 64 & $105,50 \mathrm{~A}$ & $103,90 \mathrm{~A}$ & $115,67 \mathrm{~A}$ & $115,70 \mathrm{~A}$ & $113,43 A$ & 0,7490 & 40,194 \\
\hline 71 & $94.40 \mathrm{~A}$ & $120.03 A$ & $108.43 A$ & $119.03 A$ & $101,23 \mathrm{~A}$ & 0,0440 & 27,045 \\
\hline 78 & $94,73 \mathrm{~A}$ & $120,03 \mathrm{~A}$ & $108,43 A$ & $116,20 \mathrm{~A}$ & $101,23 \mathrm{~A}$ & 0,0740 & 28,352 \\
\hline 106 & $108,43 \mathrm{~A}$ & $97,20 \mathrm{~A}$ & $108,23 A$ & $96,40 \mathrm{~A}$ & $108,23 \mathrm{~A}$ & 0,5635 & 40,114 \\
\hline 141 & $87,53 \mathrm{~B}$ & $84,07 B$ & $99,20 \mathrm{~A}$ & $88,17 \mathrm{~B}$ & $89,62 \mathrm{~B}$ & 0,0015 & 6,644 \\
\hline 162 & $60,77 \mathrm{~A}$ & $61,73 \mathrm{~A}$ & $89,51 \mathrm{~A}$ & $92,31 \mathrm{~A}$ & $87,57 \mathrm{~A}$ & 0,5370 & 83,888 \\
\hline 204 & $59,30 \mathrm{~A}$ & $73,93 \mathrm{~A}$ & $76,10 \mathrm{~A}$ & $90,91 \mathrm{~A}$ & $88,07 \mathrm{~A}$ & 0,5090 & 65,211 \\
\hline 209 & $92,70 \mathrm{~B}$ & $107,47 \mathrm{~A}$ & $95,98 B$ & $88,53 \mathrm{~B}$ & $88,57 \mathrm{~B}$ & 0,0010 & 10,989 \\
\hline 245 & $81,03 \mathrm{~A}$ & $86,53 A$ & $95,87 \mathrm{~A}$ & $89,53 \mathrm{~A}$ & $85,63 A$ & 0,3330 & 23,086 \\
\hline 294 & $96,33 \mathrm{~A}$ & $92,37 \mathrm{~A}$ & 0,000B & $82,23 A$ & $85,63 \mathrm{~A}$ & $<, 0001$ & 23,661 \\
\hline 347 & $95,57 \mathrm{~A}$ & $95,69 \mathrm{~A}$ & $84,25 \mathrm{AB}$ & $83,57 \mathrm{AB}$ & $68,61 \mathrm{~B}$ & 0,0130 & 22,361 \\
\hline
\end{tabular}

Onde: Dap: Dias após aplicação do tratamento. T1: $120 \mathrm{~m}^{3} / \mathrm{ha}$ vinhaça in natura; T2: $120 \mathrm{~m}^{3} / \mathrm{ha}$ vinhaça + $60 \mathrm{~kg}$ de ureia; T3: 20 m³/ha vinhaça concentrada; T4: $200 \mathrm{Kg}$ ureia/ha; T5: Testemunha

\section{CONCLUSÕES}

Dos resultados obtidos, considerando as condições em que o trabalho foi realizado e de acordo com a metodologia aplicada, conclui-se que:

As utilizações tanto de fertilizante nitrogenado quanto de vinhaça na cultura da cana-de-açúcar incrementam a produtividade e não alteram a qualidade tecnológica, em comparação a testemunha.

Os benefícios constatados com a aplicação de vinhaça são a elevação da disponibilidade de $\mathrm{K}^{+}$e $\mathrm{Mg}^{+2}$ no solo, e também pequena elevação do $\mathrm{pH}$, melhorando as condições de fertilidade para a cultura.

A aplicação da vinhaça "in natura" ou concentrada, com doses similares de nutrientes - potássio resulta em efeito similar.

O uso combinado de fertilizante nitrogenado e vinhaça resultam em maior produtividade da cana-de-açúcar, certamente pela combinação dos efeitos benéficos 
da vinhaça para a fertilidade do solo e pela maior disponibilidade de $\mathrm{N}$ para a planta, o que se explica pela maior disponibilidade de nitrato e de amônio no solo no tempo.

Nas análises foliares, constatou-se diferença significativa apenas para o potássio. Os tratamentos resultaram em um significativo acréscimo de potássio $(\mathrm{K})$ no caldo da cana, que refletiu na melhoria de disponibilidade do elemento no solo pela aplicação de vinhaça, este aumento de $\mathrm{K}$ no caldo, poderá ser prejudicial à produção de açúcar, contribuindo para a formação do melaço, ou seja, ocorrerá a diminuição no rendimento do processo em açúcar.

\section{REFERÊNCIAS}

ALBERS, M. Concentração de vinhaça: Tecnologia s, equipamentos, e sua integração energética numa destilaria. Anais...Jaboticabal, SP: UNESP, 2007.

ALMEIDA. J.R. O problema da vinhaça em São Paulo. Boletim $\mathbf{n}^{\circ}$ 3. Piracicaba, Instituto Zimotécnico, 24 pp. 1952.

BARBOSA, E. A. A. et al. Cana-de-açúcar fertirrigada com vinhaça e adubos minerais via irrigação por gotejamento subsuperficial: Ciclo da cana-planta. Revista Brasileira de Engenharia Agrícola e Ambiental, Campina Grande, v. 16, n. 9, p. 952-958, 2012.

BRASIL. Ministério da Agricultura, Pecuária e Abastecimento. Balanço nacional da canade-açúcar e agroenergia. Brasília, DF, 2007. 140 p.

BRASIL. Ministério da Agricultura, Pecuária e Abastecimento. Setor sucroalcooleiro: produção de cana, açúcar e álcool. Brasília, DF, 2017.

CALLE, F. R; BAJAY, S. V; ROTHMAN, H. Uso da Biomassa para produção de energia na Indústria Brasileira. Campinas: Editora Unicamp, 2005. .447p.

CAMILOTTI, F.; ANDRIOLI, I.; MARQUES, M.O.; SILVA, A.R.; TASSOJUNIOR, L.C.; NOBILE, F.O.; NOGUEIRA, G.A.; PRATI, F. Produtividade e qualidade agroindustrial da cana-de-açúcar cultivada com lodo de esgoto, vinhaça e adubos minerais. STAB: Açúcar, Álcool e Subprodutos, v. 24, p. 32-55, 2006.

CANA-DE-AÇÚCAR / (eds.) Leila Luci Dinardo-Miranda; Antonio Carlos Machado de Vasconcelos; Marcos Guimarães de Andrade Landell. Campinas: Instituto Agronômico, 2008. 882 P. p. 298-308.

CANTARELLA, H; MARCELINO, R. O uso de inibidor de urease para aumentar a eficiência da ureia. In: SIMPÓSIO SOBRE INFORMAÇÕES RECENTES PARA OTIMIZAÇÃO DA PRODUÇÃO AGRíCOLA. 1., 2006, Piracicaba. Anais... Piracicaba, 2006. v.1. p. 2 - 19.

CASAGRANDE, A. A. Tópicos de morfologia e fisiologia da cana-de-açúcar. Jaboticabal: FUNEP, 1991.

CESAR, M.A.A.; DELGADO, A.A.; SILVA, F.C. da; BRESSAN, W. Avaliação da composição mineral do caldo de cana-de-açúcar, em função de variedade e época do ano e vinhaça. Revista Usineiro, São Paulo, v.20, 1991. 26-34p. 
CETESB. Norma P4. 231, de dezembro de 2006. Vinhaça: critérios e procedimentos para aplicação no solo agrícola. Estabelece as normas para utilização de vinhaça em cana-deaçúcar. No site CETESB. Acesso em 20 jul. 2011.

CETESB. Vinhaça: critérios e procedimentos para aplicação no solo agrícola. 2006. 12 p.

CONSECANA. Manual de instruções: Conselho dos produtores de cana-de-açúcar e álcool do estado de São Paulo. 5. ed. Piracicaba, 2006.

COOPERSUCAR. Aproveitamento da vinhaça: viabilidade técnica-econômica. Piracicaba, 66p. (Boletim técnico). 1978.

CORTEZ, L.; FREIRE, W. J.; ROSILLO-CALLE, F. Biodigestion of vinasse in Brazil. Int Sugar Jnl, v.100, no. 1196, 1998.

DELGADO, A. A; CESAR, M. A. A. Tecnologia e engenharia do açúcar de cana. v. 2. Piracicaba: Departamento de Tecnologia Rural (Esalq), 1977.

ESTAÇÃO meteorológica automática. Dados meteorológicos diários. Piracicaba - SP: Departamento de ciências exatas - ESALQ - USP, 2013.

FRANCO, A. Cana-de-açúcar cultivada em solo adubado com lodo de esgoto e vinhaça: nitrogênio no sistema solo-planta, produtividade e características tecnológicas. Jaboticabal. 2003. 90f. Dissertação (Mestrado em Agronomia) - Faculdade de Ciências Agrárias e Veterinárias, Universidade Estadual Paulista, Jaboticabal, 2003.

FREIRE, W. J.; AGUIAR, M. A. Incorporação de vinhaça concentrada em dois solos distintos: Características químicas, físicas e mecânicas da mistura obtida. Engenharia Agrícola, Jaboticabal, v.13, p. 85-96, 1993.

GALDIANO L. C. Qualidade da cana-de-açúcar (Saccharum spp) submetida à aplicação de maturadores químicos em final de safra. 2008. 53 f. Dissertação \{Mestrado em Produção Vegetal\} - Faculdade de Ciências Agrárias e Veterinárias, Universidade Estadual Paulista, Jaboticabal, 2008.

GLORIA, N.A. da, SANTA ANA, A.G.; BIAGI, E. Composição dos resíduos de usina de açúcar e destilarias. Brasil Açucareiro, v. 81, n. 6, p. 78-87, 1973.

GLORIA, N.A. da. Emprego da vinhaça para fertilização. Piracicaba, Codistil, 50p. 1976.

GUERRA, J. G. M.; SOUZA, S. O. Protocolos da embrapa agrobiologia para análise de fertilidade do solo. Seropédica, RJ, n. 99, p. 6-11, 1999.

GUTIERREZ, Luiz E. et al. Efeito da aplicação da vinhaça como fertilizante sobre os teores de ácido trans-aconítico de caldo de cana-de-açúcar. Revista Anais da Esalq. Piracicaba, SP, v. 45. 2. ed. p. 453-462, 1988.

HAAG, H. P. et al. Nutrição Mineral da Cana-de-Açúcar. In: PARANHOS, S. B. \{Org\}. Canade-Açúcar: cultivo e utilização. Campinas: Ed. Fundação Cargill, 1987. p. 91-92.

HAAG, H. P.; ACCORSI, W. R. Deficiência de macro e micronutrientes em cana-de-açúcar (Saccharum spp) variedade CB 41-76 cultivada em solução nutritiva, An. Esc. Super. Agric. Luiz de Queiroz [online], v.35, p. 125-168, 1978. 
JADOSKI, C. J. et al. Fisiologia do desenvolvimento do estádio vegetativo da cana-deaçúcar (Saccharum officinarum L.). Pesquisa Aplicada \& Agrotecnologia, v.3, n. 02, p. 169-176, ago. 2010.

JANK, M. S. Uma matriz de Combustíveis para o Brasil. In: SOUZA, E. L. L; MACEDO, I. C. Etanol e bioeletricidade: A cana- de-açúcar no futuro de matriz energética. São Paulo: Ed. Luc, 2010. p. 10.

JUNIOR, C. H. A. et al. Aproveitamento Agrícola de Resíduos no Canavial. In: MARQUES, M. O. et al. Tecnologias na agroindústria canavieira. Jaboticabal: Ed. FCAV/Unesp, 2008. p. 187.

JUNQUEIRA, Cássia de A. R. et al. Identificação do potencial de contaminação de aquíferos livres por vinhaça na bacia do Ribeirão do Pântano, Descalvado (SP), Brasil.

LOPES, C. H. Tecnologia de produção de açúcar de cana. São Carlos: EdUFSCar, 2011.

MATTIAZZO, M. E. ; GLORIA, N. A. . Effect of vinasse on soil acidity.. Water Science Tecnology, Londo, v. 19, n.7, p. 1293-1296, 1987.

MATTIAZZO, M. E. ; GLÓRIA, Nadir Almeida da. Efeito da vinhaça na acidez do solo. STAB. Sociedade dos Técnicos Açucareiros e Alcooleiros do Brasil , Piracicaba, v. 4, n.2, p. 35-40, 1985.

MIRANDA, T. L. Relações entre atributos físicos e biológicos do solo após operações de colheita e aplicação de vinhaça em cana-de-açúcar. 2009. 81f. Dissertação (Mestrado) - Programa de Pós-Graduação em Engenharia Agrícola, Universidade Federal Rural de Pernambuco, Recife, $2009 . \quad$ PE, Disponível em: <www.pgea.ufrpe.br/downloads/dissertacoes/Thiciano.pdf>. Acesso em: 11 nov. 2011.

MORO, C. C. et al. Utilização da vinhaça como fertilizante no cultivo da cana de açúcar. Revista Cognitio Unilins, Lins, n. 1, 2011.

OLIVEIRA, E. L. et al. Uso de vinhaça de alambique e nitrogênio em cana-de-açúcar irrigada e não irrigada. Pesquisa Agropecuária Brasileira, Brasília, v. 44, n. 11, p. 1398-1403, Nov. 2009.

ORLANDO FILHO, J. Absorção dos macronutrientes pela cana-de-açúcar (Saccharum spp) variedade CB41-76, em três grandes grupos de solos no Estado de São Paulo. Piracicaba, 1978. 154f. Tese (Doutorado em Solos e Nutrição de Plantas) - Escola Superior de Agricultura "Luiz de Queiroz", Universidade de São Paulo. Piracicaba. 1978.

PEIXOTO, A. A.; BERTO, P. N. A.; THURLER, A. M.; ROCHA, J. P. S. M.; DELGADO, F. R. M. C. R. Efeitos de tratos culturais em cana-soca, em solo argiloso com vinhaça aplicada por caminhão. STAB: Açúcar, Álcool e Subprodutos, Piracicaba, v. 4, n. 6, p. 45-50, 1986.

PEIXOTO, Aristeu M. (coord.) et al. Vinhaça. In: Enciclopédia Agrícola Brasileira: s-z Vol. 6. 6.ed. São Paulo: Editora da Universidade s São Paulo, 2006. 554-559.

PENATTI, C. P. Adubação da Cana-de-Açúcar: 30 anos de experiência. 1. ed. Itu: Ottoni, 2013.

PENATTI, C. P.; ARAÚJO, J. V.; FORTI, J. A.; RIBEIRO, R. Doses de vinhaça e nitrogênio aplicadas em cana-soca durante quatro safras em solo LV - Usina São José da Estiva. STAB: Açúcar, Álcool e Subprodutos, Piracicaba, v. 19, n. 5, p. 38-41, 2001. 
PENATTI, C. P.; CAMBRIA, S.; BONI, P. S.; ARRUDA, F. C. O.; MANOEL, L. A. Efeitos da aplicação de vinhaça e nitrogênio na soqueira da cana-de-açúcar. São Paulo, 1988. p. 32-38. (Boletim Técnico da Coopersucar, 44).

RIPOLI, T. C. C e Marco, L. C. Biomassa de cana-de-açúcar: colheita, energia e ambiente. Piracicaba; 2009. 333p; p.3 ed: 2

RODELLA, A.A.; FERRARI, S.E. A composição de vinhaça e efeitos de sua aplicação como fertilizante da cana de açúcar. Brasil Açucareiro, Rio de Janeiro, 90(1): 6-13, 1977.

RODRIGUES, J. D. Fisiologia da cana-de-açúcar. Botucatu: Universidade Estadual Paulista Instituto de Biociências Campus de Botucatu, 1995. p. 3.

ROSSETTO, A. J. Utilização agronômica dos subprodutos e resíduos da indústria açucareira e alcooleira. In: PARANHOS, S.B. (ed.). Cana-de-açúcar: cultivo e utilização. Campinas: Fundação Cargill, 1987, v.2, p.435-504.

ROSSETTO, R.; KORNDÖRFER, G. H.; DIAS, F. L. F. Nutrição e Adubação da Cana-deaçúcar. In: MARQUES, M. O. et al. Tecnologias na agroindústria canavieira. Jaboticabal: Ed. FCAV/Unesp, 2008. p. 125-126.

SCHULTZ, N. et al. Efeito Residual da Adubação na Cana-planta e da Adubação Nitrogenada e Potássica na Cana-soca colhidas com e sem a queima da palhada. Revista Brasileira de Ciência do Solo, Viçosa, v. 34, n. 3, p. 811-820, Maio/Jun. 2010.

SILVA, F. C. Manual de análises químicas de solos, plantas e fertilizantes. 2. ed. rev. ampl. Brasília: Embrapa Informação Tecnológica, 2009.

SILVA, M. A.; JERONIMO, E. M.; LÚCIO, D. L. Perfilhamento e produtividade de cana-deaçúcar com diferentes alturas de corte e épocas de colheita. Pesquisa Agropecuária Brasileira, Brasília, n. 8, 2008.

SILVA, V. L. Estudo econômico das diferentes formas de transporte de vinhaça em fertirrigação na cana-de-açúcar. Jaboticabal, 2009. 46f. Tese (Mestrado em Agronomia) Faculdade de Ciências Agrárias e Veterinárias, Unesp, 2009.

SILVEIRA, L. Cana é a fonte renovável que mais crescerá na matriz energética. Revista Canavieiros. 2012. 1-2p.

SMITH, P; MARTINO, D; CAI, Z; GWARY, D; JANZEN, H; KUMAR, P; MCCARL, B; OGLE, S; O'MARA, F; RICE, C; SCHOLES, B; SIROTENKO, O; HOWDEN, M; MCALLISTER, T; PAN, G; ROMANENKOV, V; SCHNEIDER, U; TOWPRAYOON, S; WATTENBACH, M; SMITH, J. Greenhouse gas mitigation in agriculture. Philosophical Transactions of the Royal Society London, v. 363, p. 789-813, 2008.

SUGAWARA, L. M.; RUDORFF, B. F. T. Acompanhamento do crescimento vegetativo da cana-de-açúcar por meio de séries temporais de NDVI do sensor Modis. In: XV SIMPÓSIO BRASILEIRO DE SENSORIAMENTO REMOTO - SBSR, 15., 2011, Curitiba. Anais... Curitiba: INPE, 2011. p. 0391.

UNICA. Moagem de cana-de-açúcar e produção de açúcar e etanol - safra 2012/2013. Disponível em: <http://www.unicadata.com.br/historico-de-producao-e-moagem.php?>. Acesso em: 12 maio 2014. 
URQUIAGA, S; MALAVOLTA, E. Ureia: Um Adubo Orgânico de Potencial para a Agricultura Orgânica. Cadernos de Ciência \& Tecnologia, Brasília, v. 19, n. 2, p. 333-339, Maio/Ago. 2002.

YAMADA, T; ROBERTS, T. L. Potássio na agricultura brasileira. Piracicaba; 2005. 841p; p.481-486. 